\title{
CHARACTERIZATION OF MACROLIDE- RESISTANT NON-INVASIVE PNEUMOCOCCI IN THE PRE-VACCINE ERA IN SERBIA
}

\author{
Suncica Popovic ${ }^{1 *}$, MirJana HadnadjeV ${ }^{2}$, InA Gajic ${ }^{1}$, Vera MiJaC ${ }^{1}$, \\ DUSAN KEKIC ${ }^{1}$, ALEKSANDRA SMITRAN ${ }^{3}$, LAZAR RANIN ${ }^{1}$ and \\ NATASA OPAVSKI ${ }^{1}$ \\ ${ }^{1}$ Institute of Microbiology and Immunology, Medical Faculty University of Belgrade, \\ Belgrade, Republic of Serbia \\ ${ }^{2}$ Department of Microbiology, Institute for Pulmonary Diseases of Vojvodina, Sremska \\ Kamenica, Republic of Serbia \\ ${ }^{3}$ Faculty of Medicine, Department of Microbiology, University of Banja Luka, Banja \\ Luka, Bosnia and Herzegovina
}

(Received: 9 April 2017; accepted: 20 June 2018)

\begin{abstract}
Numerous reports have confirmed that increased macrolide use in the treatment of respiratory tract infection has contributed to the emergence of antibiotic resistance worldwide. Studies have also shown that pneumococcal vaccine can reduce pneumococcal resistance. The aim of this study was to determine the prevalence of coresistance to penicillin and other antibiotics in macrolide-resistant (MR) non-invasive pneumococcal isolates and to evaluate serotype distribution in resistant strains in the pre-vaccine era in Serbia. About $80 \%$ of MR isolates expressed the MLS phenotype with very high resistance to both erythromycin and clindamycin. A total of 132 (84.1\%) MR isolates were multiresistant, i.e., they were resistant to erythromycin, penicillin, tetracycline, and trimethoprim-sulfamethoxazole. Among $157 \mathrm{MR}$ pneumococci, 11 different serotypes were found. Four serotypes, 19F, 14, 6B, and 23F, accounted for $77.7 \%$ of all MR pneumococcal isolates. Among isolates with the cMLS phenotype, serotypes $19 \mathrm{~F}$ and 14 were predominant, whereas serotype $6 \mathrm{~A}$ was the most common among those with the M phenotype, followed by 14 . In conclusion, coresistance to macrolides and penicillin in our non-invasive pneumococcal isolates is high. The majority of tested strains $(\sim 80 \%)$ belonged to the four serotypes (19F, 14 , $6 \mathrm{~B}$, and $23 \mathrm{~F})$ that are included in all conjugate vaccine formulations.
\end{abstract}

Keywords: macrolide resistance, pneumococci, serotype, vaccine

*Corresponding author; E-mail: SuncicaPBG@gmail.com 


\section{Introduction}

Streptococcus pneumoniae (pneumococcus) is one of the most important human pathogens. It is the most common cause of community-acquired pneumonia [1-3], sinusitis, and otitis media, as well as invasive diseases, such as bacteremia, sepsis, and meningitis. Parenteral antibiotics, such as high doses of penicillin, third-generation cephalosporins, meropenem, vancomycin, and linezolid, are used for the treatment of pneumococcal invasive diseases, while treatment for non-invasive infections typically includes oral beta-lactam antibiotics, macrolides, and newer generations of fluoroquinolones.

In the past, beta-lactam antibiotics were widely used as initial empirical treatment of community-acquired respiratory tract infections (CARTI), which led to an increase in the resistance of common respiratory pathogens. Global surveillance of resistance in bacteria causing CARTI has shown that beta-lactam non-susceptibility rates increased worldwide during the 1990s and 2000s and reaching the alarming level. The Alexander Project monitored resistance in S. pneumoniae in 9-year period during 1992-2001 and reported increase of pneumococcal non-susceptibility rate to penicillin. In some countries, such as Spain and France, pneumococcal resistance to penicillin raised from $25 \%$ to $7 \%$, respectively, at the beginning of the 1990 s to $30 \%$ and $35 \%$ in 2001 [4]. Consequently, macrolides were increasingly used for the treatment of respiratory tract infections. Thereafter, a rapid worldwide increase in the prevalence of macrolide resistance associated with an increase in macrolide consumption was observed.

The report of European Antimicrobial Resistance Surveillance System for 2014 indicated that there is a large variation in pneumococcal macrolide resistance rates across Europe. In northern European countries, resistance was low (5\% to $<10 \%$ ), whereas in Mediterranean countries, Italy, Turkey, and France, resistance was $10 \%$ to $<25 \%$ and levels reached up to $35 \%-40 \%$ in Malta and Romania [5].

Resistance to macrolides in $S$. pneumoniae is mediated by two major mechanisms. First is target modification caused by a ribosomal methylase encoded by the $\operatorname{erm} B$ gene and associated with high level of resistance to all macrolides, lincosamides, and streptogramin (MLS phenotype) [6, 7]. MLS resistance can be expressed either constitutively (cMLS) or inducibly (iMLS). The second mechanism is drug efflux, encoded by the mefA gene, which results in lower level resistance ( $M$ phenotype) to 14- and 15-membered macrolides [8-10].

A nationwide surveillance study performed during 2009-2011 in Serbia indicated that non-susceptibility of invasive pneumococcal strains to penicillin and erythromycin was $34 \%$ and $36 \%$, respectively [11]. Pneumococcal conjugate 
vaccine $(\mathrm{PCV})$ was approved for introduction in Serbia's national immunization program, and it will be implemented during 2018. It is documented that PCV has profound impact on the incidence of both pneumococcal invasive and noninvasive diseases. Also, vaccines can reduce pneumococcal resistance in vaccinated and unvaccinated populations by reducing the carriage of antibiotic-resistant serotypes [12]. Assessment of changes in serotype distribution and resistance potentially related to vaccine introduction requires valid baseline values of both serotype distribution and antimicrobial resistance.

The aim of this study was to determine the prevalence of co-resistance to penicillin and other antibiotics in macrolide-resistant (MR) non-invasive pneumococcal isolates and to evaluate serotype distribution in resistant strains in the pre-vaccine era in Serbia.

\section{Materials and Methods}

\section{Bacterial isolates}

A total of 157 non-invasive MR isolates of $S$. pneumoniae from all over Serbia were collected in 2014. The pneumococci were isolated from nasal discharge and nasopharyngeal swabs (103), sputum, tracheal, and bronchial aspirates (50), and middle ear fluid (4) obtained from patients with symptoms of an acute respiratory infection presumably of bacterial etiology (sinusitis, otitis media, and pneumonia). Out of 157 strains, 111 were isolated from children (75 among $\leq 5$ years old) and 46 from adults (23 from persons $\geq 65$ years old). After isolation and identification by conventional microbial techniques in regional microbiology laboratories, strains were sent into the National Reference Laboratory for further characterization. Strain identification was confirmed in our laboratory by optochin test, latex agglutination with the Slidex pneumo-kit (bioMérieux, France), bile solubility test, and PCR for the lytA gene. Serotyping was done by the capsular swelling test (Quellung reaction) using pool antisera and factor/type antisera (Statens Serum Institut, Copenhagen, Denmark).

\section{Antibiotic susceptibility testing}

Antibiotic susceptibility testing for oxacillin, erythromycin, chloramphenicol, trimethoprim-sulfamethoxazole, and tetracyclines was carried out by the disk diffusion method using disks (Bio-Rad, USA) on Mueller-Hinton agar with 5\% defibrinated horse blood and $20 \mathrm{mg} / \mathrm{L} \quad \beta$-nicotinamide adenine dinucleotide 
(bioMérieux) according to the recommendations of European Committee on Antimicrobial Susceptibility Testing (EUCAST) [13]. Oxacillin susceptibility for screening benzylpenicillin resistance was interpreted using the recommended current EUCAST clinical breakpoints ( $\geq 20 \mathrm{~mm}$ ) [13]. Oxacillin-resistant isolates were further tested for penicillin susceptibility using E-test strips (bioMérieux). The minimum inhibitory concentrations (MICs) of penicillin were interpreted according to the EUCAST guidelines for infections other than meningitis $(S \leq 0.06 \mu \mathrm{g} / \mathrm{ml} ; R>2 \mu \mathrm{g} / \mathrm{ml})$. Intermediate and resistant isolates were collectively grouped as non-susceptible.

\section{Macrolide resistance phenotypes}

Macrolide resistance phenotypes were determined by a double disk diffusion test using erythromycin $(15 \mu \mathrm{g})$ and clindamycin $(2 \mu \mathrm{g})$ disks (Bio-Rad), as described previously [14]. The absence of an inhibition zone around both disks suggested cross-resistance to macrolides-lincosamides-streptogramin B (cMLS phenotype). Blunting of the clindamycin inhibition zone proximal to the erythromycin disk indicated inducible resistance (iMLS). Susceptibility to clindamycin with resistance to erythromycin suggested the M phenotype [15]. MICs of erythromycin and clindamycin were determined using E-test strips (bioMérieux).

\section{Statistical analysis}

Data were analyzed by descriptive statistic methods and the insignificance of the prevalence of MLS and M phenotype between children and adults was assessed using $\chi^{2}$ test.

\section{Results}

The great majority (80.9\%) of MR strains of $S$. pneumoniae tested in this study expressed MLS phenotype (Table I). Overall, 123 of 157 isolates had a cMLS phenotype with very high resistance to both erythromycin and clindamycin (MICs $\geq 256 \mu \mathrm{g} / \mathrm{ml}$ ). Only four strains had iMLS phenotype with heterogeneous MICs values of erythromycin and clindamycin. Therefore, $\mathrm{MIC}_{50}$ and $\mathrm{MIC}_{90}$ values in iMLS group of isolates could not be calculated. Approximately, one fifth of isolates showed the M phenotype with MIC values of erythromycin that did not exceed $12 \mu \mathrm{g} / \mathrm{ml}$. These strains were completely susceptible to clindamycin (Table I). There was no significant difference in the prevalence of MLS phenotype 
Table I. Macrolide resistance phenotypes among pneumococcal isolates

\begin{tabular}{|c|c|c|c|c|c|c|}
\hline \multirow[b]{2}{*}{ Phenotype } & \multirow[b]{2}{*}{ Number } & \multirow[b]{2}{*}{ Percentage $(\%)$} & \multirow[b]{2}{*}{ Antibiotics } & \multicolumn{3}{|c|}{$\mathrm{MIC}(\mu \mathrm{g} / \mathrm{ml})$} \\
\hline & & & & $\mathrm{MIC}_{50}$ & $\mathrm{MIC}_{90}$ & Range \\
\hline \multirow[t]{2}{*}{ M } & 30 & 19.12 & Erythromycin & 3 & 8 & $1.5-12$ \\
\hline & & & Clindamycin & 0.047 & 0.094 & $0.032-0.094$ \\
\hline \multirow[t]{2}{*}{ iMLS } & 4 & 2.54 & Erythromycin & - & - & 4 to $\geq 256$ \\
\hline & & & Clindamycin & - & - & 0.125 to $\geq 256$ \\
\hline \multirow[t]{2}{*}{ cMLS } & 123 & 78.34 & Erythromycin & $\geq 256$ & $\geq 256$ & $\geq 256$ \\
\hline & & & Clindamycin & $\geq 256$ & $\geq 256$ & $\geq 256$ \\
\hline
\end{tabular}

Note: MIC: minimum inhibitory concentration; MLS: macrolides, lincosamides, and streptogramin; iMLS: inducible MLS; cMLS: constitutive MLS.

in children and adults, but $\mathrm{M}$ phenotype was significantly more common in adults than in children $\left(\chi^{2}=19.08, p<0.01\right)$.

Oxacillin resistance was observed in $130(82.8 \%)$ of MR pneumococcal strains. However, according to MIC values determined by E-test, 100 of oxacillinresistant isolates were non-susceptible to penicillin, having MIC $>0.06 \mu \mathrm{g} / \mathrm{ml}$. Therefore, penicillin non-susceptibility was found in $63.7 \%$ of MR pneumococcal isolates. Among them, 10 strains were resistant to penicillin, having MIC $>2 \mu \mathrm{g} / \mathrm{ml}$, whereas $90(57.3 \%)$ strains showed intermediate resistance. In total, 57 (36.3\%) of MR pneumococcal strains were penicillin susceptible. The MIC range of penicillin for tested strains was $0.032-16 \mu \mathrm{g} / \mathrm{ml}$.

About $80 \%$ and $70 \%$ of MR non-invasive pneumococci were resistant to tetracyclines and trimethoprim-sulfamethoxazole, respectively. Chloramphenicol remains relatively active with susceptibility rate of $77 \%$ (Table II).

A total of $132(84.1 \%)$ MR isolates were multiresistant, i.e., they were resistant to three or more different antimicrobial classes: erythromycin, penicillin, tetracycline, and trimethoprim-sulfamethoxazole. The most frequently occurring phenotype included resistance to erythromycin, tetracyclines, and trimethoprimsulfamethoxazole was found in $96(61.1 \%)$ strains.

Among 157 MR pneumococci, 11 different serotypes were found, while four $(2.5 \%)$ strains were non-typable (Table III). Four serotypes, 19F $(n=51)$,

Table II. Susceptibility of macrolide-resistant $S$. pneumoniae strains to other antibiotics

\begin{tabular}{lcccc}
\hline Antibiotics & Resistant (\%) & Intermediate (\%) & Susceptible (\%) & Total (\%) \\
\hline Penicillin & $10(6.4)$ & $90(57.3)$ & $57(36.3)$ & $157(100)$ \\
Tetracycline & $124(79)$ & $0(0)$ & $33(21)$ & $157(100)$ \\
Chloramphenicol & $36(23)$ & $0(0)$ & $121(77)$ & $157(100)$ \\
Trimethoprim-sulfamethoxazole & $105(67)$ & $8(5)$ & $44(28)$ & $157(100)$ \\
\hline
\end{tabular}


Table III. Distribution of serotypes among different macrolide resistance phenotypic categories of 157 macrolide-resistant $S$. pneumoniae isolates

\begin{tabular}{lcccccr}
\hline Serotypes & $\begin{array}{c}\text { cMLS } \\
{[n(\%)]}\end{array}$ & $\begin{array}{c}\text { iMLS } \\
{[n(\%)]}\end{array}$ & $\begin{array}{c}\text { M } \\
{[n(\%)]}\end{array}$ & $\begin{array}{c}\text { Children } \\
{[n(\%)]}\end{array}$ & $\begin{array}{c}\text { Adults } \\
{[n(\%)]}\end{array}$ & $\begin{array}{c}\text { Total } \\
{[n(\%)]}\end{array}$ \\
\hline $19 \mathrm{~F}$ & $48(39.0)$ & 0 & $3(10.0)$ & $43(84.3)$ & $8(15.7)$ & $51(32.5)$ \\
14 & $33(26.8)$ & 0 & $6(20.0)$ & $33(84.6)$ & $6(15.4)$ & $39(24.8)$ \\
$6 \mathrm{~B}$ & $15(12.2)$ & 0 & $2(6.7)$ & $12(70.6)$ & $5(12.4)$ & $17(10.8)$ \\
$23 \mathrm{~F}$ & $12(9.8)$ & 0 & $3(10.0)$ & $10(66.7)$ & $5(33.3)$ & $15(9.6)$ \\
$6 \mathrm{~A}$ & $2(1.6)$ & 0 & $9(30.0)$ & $5(45.5)$ & $6(54.5)$ & $11(7.0)$ \\
$19 \mathrm{~A}$ & $5(4.1)$ & $4(100)$ & 0 & $5(55.5)$ & $4(44.5)$ & $9(5.7)$ \\
3 & $1(0.8)$ & 0 & $3(10.0)$ & $1(25.0)$ & $3(75.0)$ & $4(2.5)$ \\
$11 \mathrm{~A}$ & $2(1.6)$ & 0 & $1(3.3)$ & $1(33.3)$ & $2(66.7)$ & $3(1.9)$ \\
$15 \mathrm{~B}$ & $1(0.8)$ & 0 & $1(3.3)$ & $0(0)$ & $2(100)$ & $2(1.3)$ \\
8 & $1(0.8)$ & 0 & 0 & $0(0)$ & $1(100)$ & $1(0.7)$ \\
$23 \mathrm{~A}$ & $1(0.8)$ & 0 & 0 & $0(0)$ & $1(100)$ & $1(0.7)$ \\
Non-typable & $2(1.6)$ & 0 & $2(6.7)$ & $1(25.0)$ & $3(75.0)$ & $4(2.5)$ \\
Total & $123(100)$ & $4(100)$ & $30(100)$ & $111(100)$ & $46(100)$ & $157(100)$ \\
\hline Note: MLS: & & 0 & $0.00)$
\end{tabular}

Note: MLS: macrolides, lincosamides, and streptogramin; iMLS: inducible MLS; cMLS: constitutive MLS.

$14(n=39), 6 \mathrm{~B}(n=17)$, and $23 \mathrm{~F}(n=15)$ accounted for $77.7 \%$ of all MR pneumococcal isolates. Among isolates with the cMLS phenotype, serotypes $19 \mathrm{~F}[48 / 123(39.0 \%)]$ and 14 [33/123 (26.8\%)] were predominant, whereas serotype $6 \mathrm{~A}$ was the most common among those with the M phenotype [9/30 (30.0\%)], followed by 14 [6/30 (20.0\%)]. Interestingly, all iMLS $(n=4)$ belonged to $6 \mathrm{~A}$ serotype. The leading serotypes $19 \mathrm{~F}, 14$, and $6 \mathrm{~B}$ were significantly more common in children than in adults $(p<0.05)$. Serotypes $8,15 \mathrm{~B}$, and 23A were recovered only from adults.

Co-resistance to penicillin and erythromycin was predominantly found in MR isolates with $19 \mathrm{~F}$ serotype.

According to European Medical Agency, there is sufficient evidence that PCV10 provides protection against cross-reactive serotype 19A [16]. Therefore, we calculated the PCV10 coverage with and without serotype 19A. Coverage with PCV10 for all MR pneumococci was $77.7 \%$ (increasing to $83.4 \%$ if $19 \mathrm{~A}$ is included), whereas coverage with PCV13 was $92.9 \%$. For pediatric isolates only, coverage for PCV10 was $88.3 \%$ (92.8\% if 19A is included) and $98.2 \%$ for PVC13.

\section{Discussion}

In this study, we characterized the MR population of non-invasive respiratory tract pneumococcal isolates in Serbia. Among MR pneumococcal population, 
constitutive MLS phenotype predominated. More than $80 \%$ of isolates belonged to this phenotype, which is characterized by cross-resistance to all three classes of antibiotics - macrolides, lincosamides, and streptogramins - with extremely high MIC values $(\geq 256 \mu \mathrm{g} / \mathrm{ml})$. Only four isolates expressed inducible MLS phenotype, which is associated with susceptibility to clindamycin without induction, turning to high-level resistance after induction. M phenotype characterized by low-level erythromycin resistance and susceptibility to clindamycin was detected in almost $20 \%$ of our isolates. This phenotype was significantly more common in adults, whereas highly resistant MLS phenotype was equally distributed among isolates from children and adults.

Globally, cMLS is the most prevalent resistance phenotype among MR $S$. pneumoniae and it was more common than M phenotype. The high prevalence of ermB genotype, which mostly correlated with the cMLS phenotype, was registered in Belgium (91\%), France (90\%), Spain (88\%), Hungary (82\%), Poland (88\%), Italy (56\%), and Japan (58\%) [17-20]. By contrast, the M phenotype predominates in USA [21], Canada [22], Greece [23], Ireland, and UK [19].

A high rate of macrolide resistance among invasive pneumococci in Serbia (41\%) was previously described by Gajic et al. [11] with domination of highly resistant cMLS. It is well documented that the total macrolide use, especially longlasting antibiotics, such as azithromycin, is associated with increased macrolide resistance in S. pneumoniae [24]. In Eastern Europe, in 2011, the highest macrolide consumption was noted in Montenegro and Serbia [25]. Therefore, it is not surprising that resistance to these drugs in S. pneumoniae in Serbia reaches alarmingly high rates.

The prevalence of dual penicillin and macrolide non-susceptibility in Serbian non-invasive isolates was very high (63.7\%). However, a great majority of penicillin non-susceptible pneumococci were in the intermediate category, while $6.4 \%$ were highly resistant. The rate of penicillin and macrolide co-resistance of non-invasive pneumococcal isolates observed in this study was significantly higher compared to reports from Norway (1.7\%) [26], the Netherlands (2.7\%) [27], Czech Republic (3\%) [28], and Estonia (6\%) [29], even before the widespread use of PCV vaccination. Countries with high co-resistance rates were Greece (34.7\%) [30], Poland (39.2\%) [31], and Romania (83\%) [32]. As the decrease of resistance to both penicillin and macrolides was reported due to the PCV vaccination [33, 34], we might anticipate these changes in Serbia as well in the future.

High percentage of our erythromycin non-susceptible isolates expressed concomitant resistance to tetracycline $(\sim 80 \%)$ and/or trimethoprim-sulfamethoxazole $(\sim 70 \%)$. These patterns of resistance are widespread not only in other countries (UK and Far East) [35, 36], but also in our close proximity (Bulgaria) [37]. Typically, erm and tetracycline resistance genes are carried on the same 
transposon [38]. Therefore, we can assume that the high prevalence $(\sim 80 \%)$ of macrolide and tetracycline resistance in our isolates might be due to the insertion of transposons of the Tn916 family, but future studies should address this issue.

Eight different serotypes (19F, 14, 6B, 23F, 6A, 19A, 3, and 11A) were found among MR pneumococci in both populations and three more $(15 \mathrm{~B}, 8$, and 23A) only in adult group. Serotypes 19F, 14, 6B, and 23F, which are included in both PCV10 and PCV13, accounted for almost $80 \%$ of all MR pneumococcal isolates. The leading serotypes $19 \mathrm{~F}, 14$, and $6 \mathrm{~B}$ were significantly more common in children than in adults. It is well described that antibiotic resistance, which may provide a survival advantage, is associated with specific pneumococcal serotypes $6 \mathrm{~B}, 6 \mathrm{~A}, 9 \mathrm{~V}, 14,19 \mathrm{~F}$, and $23 \mathrm{~F}$ in the pre-vaccine era. These are predominant carriage serotypes that colonize nasopharynx of children [5]. The serotype epidemiology of MR non-invasive pneumococcal isolates in our country corresponds to distribution of pediatric serotypes in European countries in the prevaccination period [5].

The PCV has been shown to exert a profound influence on the incidence of invasive pneumococcal diseases, epidemiology of $S$. pneumoniae serotypes, as well as on the resistance. In countries with universal PCVs vaccination, vaccine serotypes have virtually disappeared [39, 40]. Serotype coverage of both PCV10 and PCV13 of our resistant $S$. pneumoniae isolated from non-invasive diseases is high $(\geq 78 \%)$. Until 2018, both PCV10 and PCV13 vaccines were licensed in Serbia, but vaccination was not compulsory and coverage is low. However, PCV is introduced in the new Law on Protection of Population against Communicable Diseases and is mandatory from March 2018. Therefore, we expect to achieve an overall reduction in pneumococcal resistance after introduction of PCVs.

In conclusion, macrolide-penicillin co-resistance in our non-invasive pneumococcal isolates is high. Four serotypes (19F, 14, 6B, and 23F) accounted for $\sim 80 \%$ of all strains. The prevailing pneumococcal serotypes in our country are included in both PCV10 and PCV13 vaccine formulations indicating good coverage. However, continuous monitoring of antimicrobial resistance and serotype distribution of $S$. pneumoniae are essential for surveillance of changes in pneumococcal population.

\section{Acknowledgements}

The authors gratefully acknowledge all colleagues for providing isolates of pneumococci. The study was partially funded by the Serbian Ministry of Education and Science (project no. 175039). 


\section{Conflict of Interest}

None.

\section{References}

1. Advisory Committee on Immunization Practices: Preventing pneumococcal disease among infants and young children. Recommendations of the Advisory Committee on Immunization Practices (ACIP). MMWR Recomm Rep 49, 1-35 (2000).

2. Robinson, K. A., Baughman, W., Rothrock, G., Barrett, N. L., Pass, M., Lexau, C., Damaske, B., Stefonek, K., Barnes, B., Patterson, J., Zell, E. R., Schuchat, A., Whitney, C. G., Active Bacterial Core Surveillance (ABCs)/Emerging Infections Program Network: Epidemiology of invasive Streptococcus pneumoniae infections in the United States, 1995-1998: Opportunities for prevention in the conjugate vaccine era. JAMA 285, 1729-1735 (2001).

3. Farha, T., Thomson, A. H.: The burden of pneumonia in children in the developed world. Paediatr Respir Rev 6, 76-82 (2005).

4. Felmingham, D., White, A. R., Jacobs, M. R., Appelbaum, P. C., Poupard, J., Miller, L. A., Grüneberg, R. N.: The Alexander Project: The benefits from a decade of surveillance. J Antimicrob Chemother 56, ii3-ii21 (2005).

5. European Centre for Disease Prevention and Control (ECDC): Antimicrobial resistance surveillance in Europe: Annual report of the European Antimicrobial Resistance Surveillance Network (EARS-Net). European Centre for Disease Prevention and Control (ECDC), Luxembourg, 2014. Available at https:/ecdc.europa.eu/sites/portal/files/media/en/publications/ Publications/antimicrobial-resistance-europe-2015.pdf

6. Leclercq, R., Courvalin, P.: Resistance to macrolides and related antibiotics in Streptococcus pneumoniae. Antimicrob Agents Chemother 46, 2727-3274 (2002).

7. Ambrose, K. D., Nisbet, R., Stephens, D. S.: Macrolide efflux in Streptococcus pneumoniae is mediated by a dual efflux pump (mel and mef) and is erythromycin inducible. Antimicrob Agents Chemother 49, 4203-4209 (2005).

8. Bley, C., van der Linden, M., Reinert, R. R.: $\operatorname{mef}(\mathrm{A})$ is the predominant macrolide resistance determinant in Streptococcus pneumoniae and Streptococcus pyogenes in Germany. Int J Antimicrob Agents 37, 425-431 (2011).

9. Del Grosso, M., Camilli, R., Iannelli, F., Pozzi, G., Pantosti, A.: The mef(E)-carrying genetic element (mega) of Streptococcus pneumoniae: Insertion sites and association with other genetic elements. Antimicrob Agents Chemother 50, 3361-3366 (2006).

10. Varaldo, P. E., Montanari, M. P., Giovanetti, E.: Genetic elements responsible for erythromycin resistance in streptococci. Antimicrob Agents Chemother 53, 343-353 (2009).

11. Gajic, I., Mijac, V., Ranin, L., Andjelkovic, D., Radicevic, M., Opavski, N.: Invasive isolates of Streptococcus pneumoniae in Serbia: Antimicrobial susceptibility and serotypes. Srp Arh Celok Lek 141, 48-53 (2013).

12. Cillóniz, C., Amaro, R., Torres, A.: Pneumococcal vaccination. Curr Opin Infect Dis 29, 187-196 (2016). 
13. The European Committee on Antimicrobial Susceptibility Testing. Breakpoint tables for interpretation of MICs and zone diameters. Version 5.0, 2015. Available at http://www. eucast.org/ast_of_bacteria/previous_versions_of_documents/

14. Montanari, M. P., Mingoia, M., Giovanetti, E., Varaldo, P. E.: Differentiation of resistance phenotypes among erythromycin-resistant pneumococci. J Clin Microbiol 39, 1311-1315 (2001).

15. Sirekbasan, L., Gönüllü, N., Sirekbasan, S., Kuşkucu, M., Midilli, K.: Phenotypes and genotypes of macrolide-resistant Streptococcus pneumoniae. Balkan Med J 32, 84-88 (2015).

16. European Medicines Agency. Summary of product characteristics, 2014. Available at http:// www.ema.europa.eu/ema/index.jsp?curl=pages/medicines/human/medicines/000973/human med_001071.jsp\&mid=WC0b01ac058001d124. (last updated on January 9, 2018).

17. Felmingham, D., Canton, R., Jenkins, S. G.: Regional trends in beta-lactam, macrolide, fluoroquinolone and telithromycin resistance among Streptococcus pneumoniae isolates 2001-2004. J Infect 55, 111-118 (2007).

18. Reinert, R. R., Reinert, S., van der Linden, M., Cil, M. Y., Al-Lahham, A., Appelbaum, P.: Antimicrobial susceptibility of Streptococcus pneumoniae in eight European countries from 2001 to 2003. Antimicrob Agents Chemother 49, 2903-2913 (2005).

19. Cantón, R., Unal, S., Farrell, D. J.: Antibacterial resistance patterns in Streptococcus pneumoniae isolated from elderly patients: PROTEKT years 1-5 (1999-2004). Int J Antimicrob Agents 30, 546-550 (2007).

20. Inoue, M., Kaneko, K., Akizawa, K., Fujita, S., Kaku, M., Igari, J., Yamaguchi, K., Kohno, S., Yamanaka, K., Iinuma, Y., Murase, M., Yokoyama, T., Asari, S., Hirakata, Y.: Antimicrobial susceptibility of respiratory tract pathogens in Japan during PROTEKT years 1-3 (1999-2002). J Infect Chemother 12, 9-21 (2006).

21. Mason, E. O. Jr., Wald, E. R., Bradley, J. S., Barson, W. J., Kaplan, S. L.: Macrolide resistance among middle ear isolates of Streptococcus pneumoniae observed at eight United States pediatric centers: Prevalence of M and MLSB phenotypes. Pediatr Infect Dis J 22, 623-627 (2003).

22. Wierzbowski, A. K., Nichol, K., Laing, N., Hisanaga, T., Nikulin, A., Karlowsky, J. A., Hoban, D. J., Zhanel, G. G.: Macrolide resistance mechanisms among Streptococcus pneumoniae isolated over 6 years of Canadian Respiratory Organism Susceptibility Study (CROSS) (1998-2004). J Antimicrob Chemother 60, 733-740 (2007).

23. Souli, M., Volonakis, K., Kapaskelis, A., Galani, I., Grammelis, V., Vorou, R., Tsivra, M., Chryssouli, Z., Katsala, D., Giamarellou, H.: Characterisation of macrolide-non-susceptible Streptococcus pneumoniae colonising children attending day-care centres in Athens, Greece during 2000 and 2003. Clin Microbiol Infect 13, 70-77 (2007).

24. Mijac, V., Opavski, N., Markovic, M., Gajic, I., Vasiljevic, Z., Sipetic, T., Bajcetic, M.: Trends in macrolide resistance of respiratory tract pathogens in the paediatric population in Serbia from 2004 to 2009. Epidemiol Infect 143, 648-652 (2015).

25. Versporten, A., Bolokhovets, G., Ghazaryan, L., Abilova, V., Pyshnik, G., Spasojevic, T., Korinteli, I., Raka, L., Kambaralieva, B., Cizmovic, L., Carp, A., Radonjic, V., Maqsudova, N., Celik, H. D., Payerl-Pal, M., Pedersen, H. B., Sautenkova, N., Goossens, H., WHO/ Europe-ESAC Project Group: Antibiotic use in Eastern Europe: A cross-national database study in coordination with the WHO Regional Office for Europe. Lancet Infect Dis 14, 381-387 (2014). 
26. Vestrheim, D. F., Hoiby, E. A., Aaberge, I. S., Caugant, D. A.: Impact of a pneumococcal conjugate vaccination program on carriage among children in Norway. Clin Vaccine Immunol 17, 325-334 (2010).

27. Bogaert, D., Sluijter, M., Toom, N. L., Mitchell, T. J., Goessens, W. H., Clarke, S. C., de Groot, R., Hermans, P. W.: Dynamics of pneumococcal colonization in healthy Dutch children. Microbiology 152, 377-385 (2006).

28. Zemlickova, H., Urbaskova, P., Adamkova, V., Motlova, J., Lebedova, V., Prochazka, B.: Characteristics of Streptococcus pneumoniae, Haemophilus influenzae, Moraxella catarrhalis and Staphylococcus aureus isolated from the nasopharynx of healthy children attending day-care centres in the Czech Republic. Epidemiol Infect 134, 1179-1187 (2006).

29. Tamm, E., Naaber, P., Maimets, M., Oona, M., Koljalg, S., Lutsar, I.: Antimicrobial susceptibility and serogroup/serotype distribution of nasopharyngeal isolates of Streptococcus pneumoniae in healthy Estonian children in 1999-2003. Clin Microbiol Infect 13, 824-826 (2007).

30. Poulakou, G., Katsarolis, I., Matthaiopoulou, I., Tsiodras, S., Kanavaki, S., Hatzaki, D., Roilides, E., Sofianou, D., Kavaliotis, I., Kansouzidou, A., Kafetzis, D. A., Paraskakis, I., Foustoukou, M., Daikos, G. L., Syriopoulou, V., Pangalis, A., Leveidiotou, S., Giamarellou, H., Hellenic Study Group for the Susceptibility of Streptococcus pneumoniae: Nationwide surveillance of Streptococcus pneumoniae in Greece: Patterns of resistance and serotype epidemiology. Int J Antimicrob Agents 30, 87-92 (2007).

31. Korona-Glowniak, I., Niedzielski, A., Malm, A.: Upper respiratory colonization by Streptococcus pneumoniae in healthy pre-school children in south-east Poland. Int J Pediatr Otorhinolaryngol 75, 1529-1534 (2011).

32. Falup-Pecurariu, O., Bleotu, L., Zavarache, C., Peled, N., Anton, O., Robu, M., Falup-Pecurariu, C., Rogozea, L., Porat, N., Greenberg, D., Dagan, R., Leibovitz, E.: Streptococcus pneumoniae nasopharyngeal colonization in children in Brasov, Central Romania: High antibiotic resistance and coverage by conjugate vaccines. Pediatr Infect Dis J 30, 76-78 (2011).

33. Angoulvant, F., Cohen, R., Doit, C., Elbez, A., Werner, A., Béchet, S., Bonacorsi, S., Varon, E., Levy, C.: Trends in antibiotic resistance of Streptococcus pneumoniae and Haemophilus influenzae isolated from nasopharyngeal flora in children with acute otitis media in France before and after 13 valent pneumococcal conjugate vaccine introduction. BMC Infect Dis 15, 236 (2015).

34. Daana, M., Rahav, G., Hamdan, A., Thalji, A., Jaar, F., Abdeen, Z., Jaber, H., Goral, A., Huppert, A., Raz, M., Regev-Yochay, G., PICR Study Group: Measuring the effects of pneumococcal conjugate vaccine (PCV7) on Streptococcus pneumoniae carriage and antibiotic resistance: The Palestinian-Israeli Collaborative Research (PICR). Vaccine 33, 1021-1026 (2015).

35. Sheppard, C., Fry, N.K., Mushtaq, S., Woodford, N., Reynolds, R., Janes, R., Pike, R., Hill, R., Kimuli, M., Staves, P., Doumith, M., Harrison, T., Livermore, D. M.: Rise of multidrugresistant non-vaccine serotype 15A Streptococcus pneumoniae in the United Kingdom, 2001 to 2014. Euro Surveill 21, 30423 (2016).

36. Park, M., Kim, H. S., Kim, H. S., Park, J. Y., Song, W., Cho, H. C., Kim, J. S.: Novel levofloxacin-resistant multidrug-resistant Streptococcus pneumoniae serotype 11A isolates, South Korea. Emerg Infect Dis 22, 1978-1980 (2016). 
37. Setchanova, L. P., Alexandrova, A., Dacheva, D., Mitov, I., Kaneva, R., Mitev, V.: Dominance of multidrug-resistant Denmark (14)-32 (ST230) clone among Streptococcus pneumoniae serotype 19A isolates causing pneumococcal disease in Bulgaria from 1992 to 2013. Microb Drug Resist 21, 35-42 (2015).

38. Brenciani, A., Bacciaglia, A., Vecchi, M., Vitali, L. A., Varaldo, P. E., Giovanetti, E.: Genetic elements carrying erm $(B)$ in Streptococcus pyogenes and association with tet $(M)$ tetracycline resistance gene. Antimicrob Agents Chemother 51, 1209-1216 (2007).

39. Richter, S. S., Heilmann, K. P., Dohrn, C. L., Riahi, F., Diekema, D. J., Doern, G. V.: Pneumococcal serotypes before and after introduction of conjugate vaccines, United States, 1999-2011. Emerg Infect Dis 19, 1074-1083 (2013).

40. Weinberger, D. M., Malley, R., Lipsitch, M.: Serotype replacement in disease after pneumococcal vaccination. Lancet 378, 1962-1973 (2011). 